CLADOCERA

\title{
Preface
}

\author{
Marina Manca $\cdot$ Piet Spaak
}

Published online: 1 August 2013

(C) Springer Science+Business Media Dordrecht 2013

In August 1985, Frey and Forró, introducing the special issue of Hydrobiologia that contained contributions of the participants of the First International Symposium on Cladocera, indicated that their initiative was inspired by a need to offer Cladoceraspecialists a platform that had already been successfully established for researchers investigating other specific taxonomical groups of organisms. This goal could be achieved thanks to the former Editor-in-Chief of Hydrobiologia, Henri Dumont.

That first meeting was also the occasion at which the "Cladocera Newsletter" was launched, something we might nowadays call a "social network" of specialists in different research fields, pertaining to different institutions, from museums to the Academia, unified by a common interest in Cladocera. A first list of "cladocerologists" from all from over the world was sent a questionnaire for putting together a

Guest editors: Marina Manca \& Piet Spaak / Cladocera: Proceedings of the 9th International Symposium on Cladocera

M. Manca $(\bowtie)$

CNR ISE, Largo Tonolli 50, 28922 Verbania, VB, Italy

e-mail:m.manca@ise.cnr.it

\section{P. Spaak}

Eawag, Swiss Federal Institute of Aquatic Science and Technology, Dübendorf, Switzerland

\section{P. Spaak}

Institute of Integrative Biology, ETH Zurich, Zurich, Switzerland database containing information on reference topics. This initiative became a success, as over 100 Cladocera specialists sent the requested information within a few months, and this lead to the publication of the first issue of the Cladocera Newsletter, in 1988. This first issue of the newsletter identified eight research topics which, over the years, became differently represented in the scientific arena, namely: (1) Systematics and distribution (temperate, tropical, arctic regions); (2) Morphology; (3) Cytology; (4) Physiology (metabolism, development and growth, reproduction, osmoregulation); (5) Ecology (community structure, population dynamics and production, seasonal succession, long-term evolution, trophic interactions, paleoecology); (6) Genetics (ecological genetics, ecology and coexistence of clones, biochemical genetics); (7) Modelling; (8) Large-scale cultivation. Genera and families of special interest were also provided by each participant. The 25 pages of this first issue, were more than doubled in the second one, in which, among others, announcement and material for the second Symposium on Cladocera in Tatranska Lomnica (CR) was provided. With this newsletter, a gap in communication was filled that is now fast and efficiently covered by a click in the internet.

It is in the same spirit of serving communication and exchange of ideas among scientists working on Cladocera that initiated the IX International Symposium on Cladocera in 2011, organized close to the "Istituto di Pallanza". We were happy that we could continue the Cladocera symposium after the VIIIth 


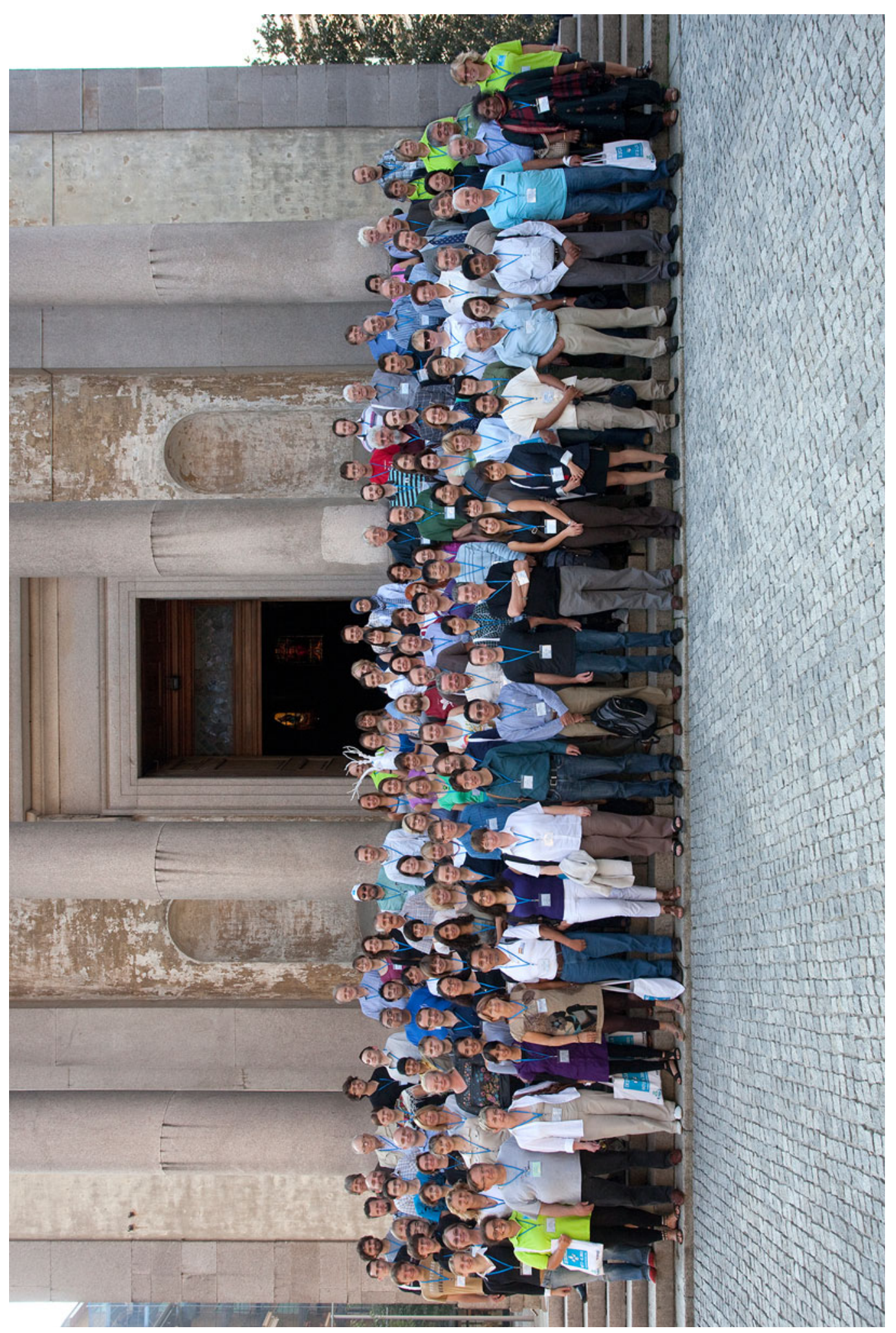




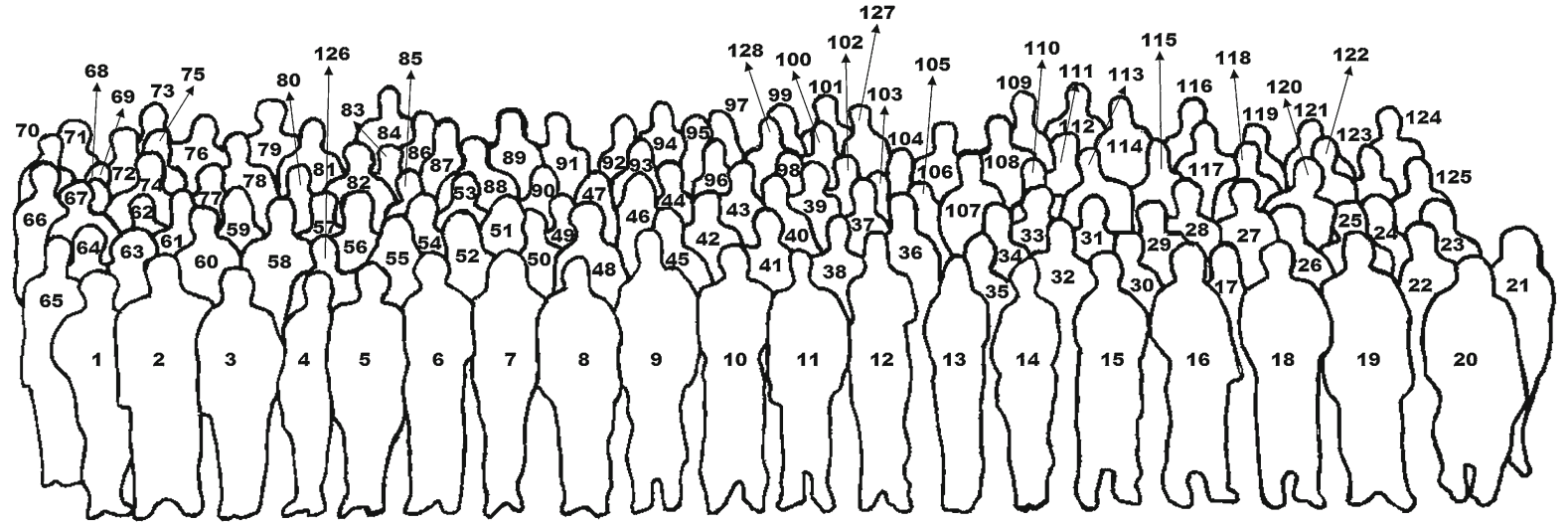

Key to the photograph from the Nineth International Symposium on Cladocera, 2-8 October 2011 Verbania, Italy

\begin{tabular}{|c|c|c|c|c|c|}
\hline 1 & Maria Colombini & 44 & Adinda Putman & 87 & Hilde Eggermont \\
\hline 2 & Elena Zuykova & 45 & Dietmar Straile & 88 & Mr. Wojtal-Frankiewicz \\
\hline 3 & Nickolai Bochkarev & 46 & Barbara Pietrzak & 89 & Lawrence J. Weider \\
\hline 4 & Claudia Romina Aguilar Acosta & 47 & Sanni Aalto & 90 & Katja Pulkkinen \\
\hline 5 & Bernadette Pinel-Alloul & 48 & Scott Peacor & 91 & Andy Dzialowski \\
\hline 6 & Jesùs Morales Ventura & 49 & Ora Johannsson & 92 & Aline Waterkeyn \\
\hline 7 & Faten Gabsi & 50 & Nina Schlotz & 93 & Sabine Navis \\
\hline 8 & Bettina Zeis & 51 & Liisa Nevalainen & 94 & Amedeo Fadda \\
\hline 10 & Fernando Martinez-Jeronimo & 53 & Adrianna Wojtal-Frankiewicz & 96 & Veerle Lemaire \\
\hline 11 & Kay Van Damme & 54 & Magdalena Suchora & 97 & Roberta Piscia \\
\hline 12 & Jorge Martinez-Martinez & 55 & Izabela Zawiska & 98 & Marina Manca \\
\hline 13 & Jennifer Korosi & 56 & Andrea Bertolo & 99 & Dörthe Becker \\
\hline 14 & Natalie Kim & 57 & Viacheslav Krylov & 100 & Nita Kaupang Shala \\
\hline 15 & Jose Martin Romero & 58 & Larisa Litvinchuk & 101 & Marcin Wojewodzic \\
\hline 16 & Z. Maciej Gliwicz & 59 & Ann Kristin Schartau & 102 & Adriana Güntzel \\
\hline 18 & S.S.S. Sarma & 61 & Magdalena Markowska & 104 & Eliana Aparecida Panarelli \\
\hline 19 & Moshe Gophen & 62 & Olivia Hesse & 105 & Patricia Hoffmann \\
\hline 20 & S. Nandini & 63 & Barbara Leoni & 106 & Winfried Lampert \\
\hline 21 & Arianne Maniglia & 64 & Martha Patricia Celis-Salgado & 107 & Craig Williamson \\
\hline 22 & Leonard Polishchuk & 65 & Dalia Aidukaite & 108 & José Roberto Debastiani Junior \\
\hline 23 & José Luis Gama-Flores & 66 & Christoph Tellenbach & 109 & Thomas Correll Jensen \\
\hline 24 & Maria Elena Huidobro Salas & 67 & Markus Möst & 110 & Petr Jan Juracka \\
\hline 25 & Jiri Machacek & 68 & Sho Kimijima & 111 & Norman Yan \\
\hline 26 & Martin Cerny & 69 & Sabine Giessler & 112 & Joseph Simonis \\
\hline 27 & Irina Blinova & 70 & Benjamin Alric & 113 & Adam Petrusek \\
\hline 28 & Inna Morozova & 71 & Quirin Herzog & 114 & Piotr Dawidowicz \\
\hline 29 & Takayuki Hanazato & 72 & Max Rabus & 115 & Dominik Martin-Creuzburg \\
\hline 30 & Olga Dubovskaya & 73 & Steven Declerck & 116 & Jaromir Seda \\
\hline 31 & Ivana Vanickova & 74 & Wolfgang Engelbrecht & 117 & Howard Riessen \\
\hline 32 & Zhanna Buseva & 75 & Piotr Bernatowicz & 118 & W.Gary Sprules \\
\hline 35 & Miyuki Inoue & 78 & Anna Sikora & 121 & Hannah Robson \\
\hline 36 & Boping Han & 79 & Christian Küster & 122 & Miroslaw Slusarczyk \\
\hline 37 & Lei Xu & 80 & Araceli Adabache-Ortiz & 123 & Sarah Wolf \\
\hline 38 & Dan Cheng & 81 & Jacek Radzikowski & 124 & Christian Laforsch \\
\hline 39 & Bjorn Walseng & 82 & Marcelo Silva-Briano & 125 & Esther Keller \\
\hline 40 & Bernard Clement & 83 & Diego de Jesus Chaparro-Herrera & 126 & Esmeralda Bravo-Hernandez \\
\hline 41 & Miguel Alonso & 84 & Rainer Deneke & 127 & Marwa Jalal \\
\hline 42 & Anna Bednarska & 85 & Rocio Fernandez & 128 & Marte Rosnes \\
\hline 43 & Artem Sinev & 86 & Maria Belyaeva & & \\
\hline
\end{tabular}


symposium in Aguascalientes, Mexico. Between October 2nd and 8th, 2011 researchers from 24 countries found their way to the southern slide of the Alps from which, two centuries before, the existence of a "true pelagic fauna" in lakes was supported by Weissman's finding of Leptodora hyalina (=Leptodora kindtii Focke). The success of the Symposium is testified by the large number of attendants, constrained by the organizers for practical reasons to a number of ca. 130. In the present issue, we collect 20 scientific contributions that illustrate the diversity of the contributions that were presented during the symposium.

On the cover of this special issue, we reproduce a plate that, to our knowledge, was never used again after its initial publication in 1820. It was carefully scanned from an original water color print of a book one of us (M. Manca) found on a shelf of the old library at the Istituto di Pallanza: "Histoire du Monocles" (Jurine, 1820). In this book, Jurine reported results of a 10-year study on "Monocle qui se trouvent aux environs de Genève" (Ponds that are near Geneva). Poorly known, especially to young scientists, Jurine was indeed very modern in his scientific approach. He focused on living organisms and aimed at taking into account, among others, the differing body sizes of Cladocera taxa. Not by chance, his plates also include embryonic developmental stages and a picture of Daphnia mating, the latter linked to a beautiful painting of an ephippial organism. Also an illustration of how body parts can become Cladocera subfossil remains in the sediments is provided in remarkable detail.

At the end of the conference it was decided that we will meet again in 2014 in the Czech Republic where the team around Adam Petrusek will organize the 10th International Symposium on Cladocera.

\section{References}

Frey, D. G. \& L. Forró, 1985. Preface. Hydrobiologia 145: $\mathrm{V}-\mathrm{VI}$.

Jurine, L., 1820. Histoire Des Monocles Qui Se Trouvent Aux Environs de Genève. J.J. Paschoud, Imprimeur-Libraire, Paris. 